\title{
Dislipidemias e antipsicóticos atípicos
}

\author{
Dyslipidemias and atypical antipsychotics
}

Edilberto Amorim de Cerqueira Filho, Fernanda de Sena Arandas, Irismar Reis de Oliveira e Eduardo Pondé de Sena

\begin{abstract}
Resumo
Objetivo: Um progressivo número de evidências surge associando o uso de antipsicóticos atípicos a dislipidemias, situação pouco atentada por considerável número de psiquiatras e preditora importante de doenças cardiovasculares (DCVs) e de morbimortalidade. 0 propósito deste estudo é revisar a associação entre o uso de antipsicóticos atípicos e 0 desenvolvimento de dislipidemias em pacientes com esquizofrenia. Métodos: A pesquisa bibliográfica utilizou os bancos de dados MEDLINE e Scientific Electronic Library Online (SciELO), com os descritores: schizophrenia, dyslipidemia, hyperlipidemia e lipids, para identificar artigos originais publicados no período de 1997 a setembro de 2006. Resultados: Os artigos foram agrupados segundo cada agente terapêutico, de acordo com o seu impacto sobre o perfil lipídico. Conclusão: Observa-se maior risco de desenvolvimento de dislipidemias em pacientes com esquizofrenia em uso de alguns antipsicóticos atípicos. Intervenções comportamentais e farmacológicas devem ser associadas nos indivíduos com esquizofrenia em tratamento antipsicótico e que desenvolvem dislipidemias.

Palavras-chave: esquizofrenia, dislipidemia, hiperlipidemia, lípides.
\end{abstract}

\begin{abstract}
Objective: Pieces of evidence appear associating the use of atypical antipsychotics to dyslipidemias, situation that is of little attention by considerable number of psychiatrists and important predictor of cardiovascular illnesses and morbi-mortality. The intention of this study is to review the association between the atypical antipsychotic use and the development of dyslipidemias in patients with schizophrenia. Methods: The bibliographical research used databases MEDLINE and SciELO, for the key words: schizophrenia, dyslipidemia, hyperlipidemia and lipids, with the objective to identify original articles published in the period of 1997 to September 2006. Results: The articles were distributed according to each therapeutic agent and their impact on lipidic profile. Conclusion: Higher risk of development of dyslipidemias in schizophrenic patients in use of some atypical antipsychotics is observed. Behavioral and pharmacological interventions must be associated in the treatment of subjects with schizophrenia in antipsychotic therapy who develop dyslipidemias.

Key words: schizophrenia, dyslipidemia, hyperlipidemia, lipids.
\end{abstract}

Escola Bahiana de Medicina e Saúde Pública (Cerqueira Filho EA) Hospital Universitário Professor Edgard Santos (Arandas FS) Departamento de Neuropsiquiatria da Universidade Federal da Bahia (UFBA) (Oliveira IR)

Correspondência para: Edilberto Amorim de Cerqueira Filho

Rua Banco dos Ingleses, 8/9 - Campo Grande - 40080-040 - Salvador-BA

- e-mail: edilbertoamorim @gmail.com 


\section{Introdução}

O impacto positivo dos antipsicóticos atípicos (APAs) no manejo da esquizofrenia é incontestável. Seu maior ganho em relação ao uso dos antipsicóticos convencionais consiste na redução dos sintomas extrapiramidais, havendo, ainda, melhor eficácia em relação aos sintomas negativos, afetivos e cognitivos (Keefe, 1999; Silva de Lima et al., 2005).

Entretanto, apesar dos benefícios envolvidos com 0 advento dos APAs, seu uso está associado ao aumento da prevalência de distúrbios metabólicos como obesidade, diabetes tipo 2, síndrome metabólica (SM) e dislipidemias. A literatura psiquiátrica tem produzido avanços na abordagem dos efeitos metabólicos dos APAs na esquizofrenia; contudo, apesar das tentativas, ainda não existe um protocolo ideal para o manejo desses pacientes (Consensus Development Conference on Antipsychotic Drugs and Obesity and Diabetes, 2004).

O objetivo deste estudo é realizar uma revisão da literatura acerca da associação entre uso de antipsicóticos atípicos e desenvolvimento de dislipidemias, seus determinantes e impacto no indivíduo portador de esquizofrenia. Com foco em triglicérides (TGs), colesterol total (CT), colesterol da lipoproteína de baixa densidade (LDL-C) e colesterol da lipoproteína de alta densidade (HDL-C), visa, igualmente, avaliar se, nessa população especial, essas alterações lipídicas representam preditores intimamente associados ao desenvolvimento de doenças cardiovasculares (DCVs), tal como ocorre na população geral (Knopp, 1999).

\section{Métodos}

Os artigos consultados para esta revisão foram resultados de busca nos bancos de dados MEDLINE e Scientific Electronic Library Online (SciELO), referentes ao período de janeiro a setembro de 2006. Foram utilizados como descritores primários: schizophrenia, dyslipidemia, hyperlipidemia e lipids. Foram excluídos artigos escritos em outras línguas que não a inglesa ou a portuguesa ou aqueles a que não se tem acesso no Brasil. Artigos anteriores a 1997 foram obtidos por meio das referências bibliográficas dos artigos selecionados através das bases de dados.

\section{O impacto dos antipsicóticos atípicos}

\section{Qualidade de vida versus maior risco de distúrbios metabólicos}

A esquizofrenia cursa com um grande comprometimento funcional, resultando num grande impacto na produtividade e na qualidade de vida dos seus portadores. Em estudo realizado em São Paulo, Menezes e Mann (1993) encontraram uma taxa de mais de $80 \%$ de diminuição no funcionamento social de pacientes com esquizofrenia, sendo que, desses, $50 \%$ tinham um funcionamento ruim ou muito ruim e $30 \%$ não possuíam fonte de renda, sendo custeados inteiramente pela família ou por amigos. Cerca de $50 \%$ dos pacientes permanecem solteiros e $32 \%$ se divorciaram (Helgason, 1990). Durante esse período, os APAs ainda não estavam consolidados no mercado como alternativa de tratamento.
Os APAs apresentam eficácia superior aos antipsicóticos típicos nos aspectos cognitivos. Dessa forma, a fluência verbal, a memória e a atenção dos pacientes é melhorada, possibilitando um maior grau de interação com o ambiente. Com a melhora cognitiva, melhoram o funcionamento social e as chances de obtenção ou manutenção do emprego (Stip et al., 1999). Silva de Lima et al. (2005) acompanharam, por um período de nove meses, 197 pacientes: 104 em uso de olanzapina e 93 com antipsicóticos típicos. Os pacientes em uso de olanzapina cursaram com melhora da sintomatologia conforme avaliação na Escala das Síndromes Negativa e Positiva (PANSS) $(p=0,02)$ e nos itens funcionamento físico, limitações físicas e limitações emocionais da escala de qualidade de vida SF 36, apesar de o funcionamento social não ter alcançado significância $(p=0,17)$.

A expectativa de vida das pessoas com esquizofrenia é cerca de $20 \%$ inferior à da população geral (Casey, 2004). 0 número de mortes, com pareamento por idade, está aumentado de 1,6 a três vezes. O suicídio contribui com cerca de 10\% a $13 \%$, havendo estudos contabilizando-o em até $38 \%$ das mortes (Casey, 2004), oito vezes mais que na população geral (Caldwell e Gottesman, 1990).

Os APAs também são eficazes nos sintomas depressivos associados à esquizofrenia, tendo boa resposta no fenômeno do suicídio, particularmente a clozapina. Meltzer e Okayli (1995) avaliaram 88 pacientes refratários ao tratamento que estavam sob uso de clozapina nos seis meses anteriores, encontrando redução de $86 \%$ no total de tentativas de suicídio com o seguimento.

Dessa forma, o impacto dos APAs na qualidade de vida dos pacientes portadores de esquizofrenia é muito positivo, tendo o seu lugar já consolidado na terapêutica atual. Entretanto não podemos avaliar a situação por apenas uma perspectiva, pois, apesar de bem tolerados, os APAs são responsáveis por uma série de distúrbios metabólicos intimamente associados ao desenvolvimento de DCV.

A DCV é a maior causa de mortalidade entre pacientes esquizofrênicos, correspondendo a $34 \%$ das mortes entre homens e $31 \%$ entre mulheres. As neoplasias correspondem a $13 \%$ e $16 \%$ e doenças respiratórias, a $8 \%$ e $9 \%$, respectivamente (Brown, 1997). Henderson et al. (2005) estimaram aumento de $9 \%$ no risco de DCV naqueles pacientes que fizeram uso de clozapina pelo período equivalente a dez anos. Fontaine et al. (2001), baseando-se em amostra do estudo de Framingham, estimaram aumento equivalente a 416/100 mil mortes por DCV induzidas pelo ganho ponderal de aproximadamente $10 \mathrm{~kg}$ com o mesmo tratamento em dez anos, enquanto que, equivalentemente, 492/100 mil suicídios seriam evitados, reduzindo sobremaneira o impacto benéfico do tratamento sob esse aspecto. Cerca de $68 \%$ dessa população são fumantes, fator de risco independente para aparecimento de DCV, e $27 \%$ são portadores de hipertensão, cursando a população geral com taxas de $35 \%$ e $17 \%$, respectivamente (Goff et al., 2005). Goff et al. (2005) analisaram amostra do Clinical Antipsychotic Trials of Intervention Effectiveness (CATIE) envolvendo 689 pacientes e encontraram risco de desenvolvimento de DCV em dez anos significantemente elevado comparando-se a população esquizofrênica com 
controles sadios (34\% entre homens e $50 \%$ entre mulheres). A comparação entre risco de DCV e entre APA e típicos necessita de estudos mais específicos. Brown (1997), numa metanálise envolvendo estudos anteriores à consolidação dos APAs, encontrou uma taxa de risco de DCV de 12\%. Cohn et al. (2004) não encontraram diferenças de risco para DCV e Enger et al. (2004) também não as observaram no risco para desenvolvimento de infarto agudo do miocárdio (IAM).

Obesidade, diabetes, síndrome metabólica (SM) e dislipidemias estão no cerne do desenvolvimento das DCVs. Estão intimamente ligadas ao fenômeno da aterosclerose, que é responsável por cerca de $50 \%$ das mortes na população americana (Knopp, 1999). As metas lipídicas preconizadas para a prevenção da doença aterosclerótica segundo a I Diretriz Brasileira de Diagnóstico e Tratamento da Síndrome Metabólica estão descritas na Tabela 1.

Tabela 1. Metas lipídicas propostas para a prevenção da doença aterosclerótica

\begin{tabular}{lllll}
\hline & Baixo risco & $\begin{array}{l}\text { Médio } \\
\text { risco }\end{array}$ & Alto risco & $\begin{array}{l}\text { Muito alto } \\
\text { risco }\end{array}$ \\
\hline $\mathrm{LDL}-\mathrm{C}$ & $<160^{*}$ & $\begin{array}{l}<130 \\
(<100)^{\star *}\end{array}$ & $<100$ & $<70^{\star *}$ \\
$(\mathrm{mg} / \mathrm{dl})$ & & $>40$ & $>40$ \\
$\mathrm{HDL}-\mathrm{C}$ & $>40$ & $>40$ & $(>45$ se DM2) & $(>45$ se DM2 $)$ \\
$(\mathrm{mg} / \mathrm{dl})$ & & & & $<150$ \\
$\mathrm{TG}$ & $<150$ & $<150$ & $<150$ & \\
$(\mathrm{mg} / \mathrm{dl})$ & & & & \\
\hline
\end{tabular}

Fonte: I Diretriz Brasileira de Diagnóstico e Tratamento da Síndrome Metabólica. *Valor tolerado (recomenda-se LDL-C $<130 \mathrm{mg} / \mathrm{dl}$ ao grupo de baixo risco de acordo com as III Diretrizes Brasileiras de Dislipidemias e Prevenção da Aterosclerose; **valor opcional baseado na atualização do Adult Treatment Panel III (ATP III); LDL-C: colesterol da lipoproteína de baixa densidade; HDLC: colesterol da lipoproteína de alta densidade; DM2: diabetes mellitus tipo 2; TG: triglicérides.

Discorrer-se-á sobre a prevalência dos distúrbios metabólicos na população esquizofrênica e do impacto dos APAs em cada uma delas devido à grande influência desses fatores no fenômeno das dislipidemias.

\section{Distúrbios metabólicos e APA}

\section{Obesidade}

A prevalência de obesidade na população esquizofrênica medicada é grande, ficando em torno de $50 \%$ (Baptista, 1999). A clozapina e a olanzapina são responsáveis pelo maior ganho de peso, enquanto a ziprasidona e o aripiprazol parecem não induzir ganho ou determinar apenas um mínimo ganho ponderal (Alisson et al., 1999; Consensus Development Conference on Antipsychotic Drugs and Obesity and Diabetes, 2004). Em estudos de curta duração, a olanzapina levou a um aumento de dez vezes no ganho de peso em relação ao placebo; a quetiapina, de quatro vezes; e a risperidona, a ziprasidona e 0 aripiprazol, de cerca de duas vezes (Casey, 2004). Quando é realizada estratificação por idade dos grupos, a população jovem possui maior risco de ganho de peso (Kelly, 2005; Wetterling e Mubigbrodt, 1999).
Entretanto o ganho ponderal pode estar relacionado ao grau de resposta clínica no caso da clozapina (Lamberti et al., 1992; Leadbetter et al., 1992) e da olanzapina (Garyfallos et al., 2003). Deve ser levado em conta também que o peso anterior à terapia com APA é fator de risco para desenvolvimento de obesidade e que pacientes obesos possuem risco 2,5 vezes maior de não-adesão ao tratamento (Weiden et al., 2004).

\section{Diabetes tipo 2}

Estudos demonstram a evidência de maior risco de desenvolvimento de diabetes tipo 2 na população esquizofrênica, tendo um deles demonstrado taxa de prevalência entre 11,1\% e $12,5 \%$ nesses pacientes (Dixon et al., 2000) contra 6,2\% da população geral. Numa análise do estudo CATIE envolvendo 689 pacientes, $13 \%$ eram portadores de diabetes contra 3\% dos controles (Goff et al., 2005). O risco com o uso dos APAs é ainda maior. Henderson et al. (2005) avaliaram 96 pacientes por um período de dez anos sob uso de clozapina, estimando $43 \%$ de surgimento de diabetes tipo 2 nessa população. Koro et al. (2002) observaram risco muito aumentado de diabetes em pacientes sob uso de olanzapina em relação a pacientes saudáveis (odds ratio [OR]: 5,8 ) ou mesmo àqueles em uso de risperidona.

\section{Síndrome metabólica}

O uso de antipsicóticos está associado ao aumento do risco de desenvolvimento de SM (McEvoy et al., 2005). Diversos estudos têm mostrado maior incidência de SM na população esquizofrênica. No estudo americano CATIE 689 pacientes foram avaliados, encontrando-se uma taxa de $40,9 \%$ de incidência de SM contra $23,7 \%$ na população geral. Esse risco é ainda maior para as mulheres, que possuem 2,5 vezes maior risco de desenvolver SM quando comparadas às mulheres da população geral (McEvoy et al., 2005). Pacientes esquizofrênicos com SM tiveram maior positividade em sua história para DCV quando comparados a pacientes do mesmo grupo sem SM $(25,8 \%$ contra 12,5\%; $p=0.01$ ) (Haag et al., 2006).

0 perfil de alteração metabólica de cada APA é consideravelmente variado no desenvolvimento de cada tipo de evento (Tabela 2).

Tabela 2. Os APAs e seus efeitos metabólicos

\begin{tabular}{llll}
\hline Droga & $\begin{array}{l}\text { Ganho de } \\
\text { peso }\end{array}$ & $\begin{array}{l}\text { Risco de } \\
\text { diabetes }\end{array}$ & $\begin{array}{l}\text { Piora do perfil } \\
\text { lipídico }\end{array}$ \\
\hline Clozapina & +++ & + & + \\
Olanzapina & +++ & + & + \\
Risperidona & ++ & $\mathrm{D}$ & $\mathrm{D}$ \\
Quetiapina & ++ & $\mathrm{D}$ & $\mathrm{D}$ \\
Aripiprazol & $+/-$ & - & - \\
Ziprasidona & $+/-$ & - & -
\end{tabular}

Fonte: Consensus Development Conference on Antipsychotic Drugs and Obesity and Diabetes, 2004.

*Novas drogas com estudos de acompanhamento de longo prazo limitados; + = aumento; - = sem efeito; $D$ = resultados discrepantes. 


\section{Mecanismo de ação das dislipidemias no uso de APA}

0 mecanismo através do qual os APAs geram hiperlipidemia e os demais componentes da SM ainda não foram completamente esclarecidos. A resistência à insulina, entretanto, insinua-se como fator central desse mecanismo, vez que se associa ao aumento de TGs e LDL, além de diminuir o HDL-C. Essa teoria foi fortalecida em estudo com 14 pacientes tratados com olanzapina, com média de acompanhamento de cinco meses, que mostrou que a maioria dos pacientes tinha hiperinsulinemia, hiperlipidemia e hiperleptinemia, com níveis de TGs e índice de massa corporal (IMC) correlacionados com os de glicose e insulina (Melkersson et al., 2000). Esses resultados sugerem que a olanzapina talvez cause hiperinsulinemia, induzindo diretamente resistência periférica à insulina em nível celular, não afastando as hipóteses de um efeito direto no metabolismo lipídico e gerando, secundariamente, resistência insulínica ou hiperinsulinemia, ou até mesmo um efeito direto da droga nas células beta pancreáticas e na secreção insulínica. 0 estudo, no entanto, não apresenta grupo controle ou dados laboratoriais prévios ao uso da droga para comparação, o que limita sua validade.

Para avaliar os efeitos da olanzapina e da risperidona na função das células beta em indivíduos saudáveis, Sowell et al. (2002) utilizaram o clamp hiperglicêmico em 48 pacientes tratados com essas drogas ou placebo, observando redução da sensibilidade insulínica (aproximadamente $18 \%$ ) e aumento na resposta da insulina à hiperglicemia (aproximadamente 25\%), sem diferenças nesses dois parâmetros na análise multivariada quando se excluía 0 impacto do ganho ponderal. Não houve evidências de que essas drogas diminuíssem a resposta secretória da insulina em resposta à hiperglicemia prolongada.

Outro estudo demonstra hiperinsulinemia em pacientes tratados com olanzapina (Bouchard et al., 2001). A pesquisa, com objetivo de comparar risco cardiovascular em indivíduos tratados com olanzapina e risperidona, mostrou que $32 \%$ do primeiro grupo tinham a tríade de hiperinsulinemia, elevação de apolipoproteína B (Apo B) e LDL pequena e densa, em comparação com $5 \%$ dos pacientes do segundo grupo, a despeito de IMCs similares.

Os derivados dibenzodiazepínicos têm os efeitos mais significativos nos TGs. Clozapina, olanzapina e quetiapina, com estrutura em anel-3, semelhante ao núcleo fenotiazídico, dividem com eles a propensão de aumentar TGs de forma muito mais importante que o colesterol total (Meyer, 2001). No entanto o mecanismo exato dessas alterações ainda não foi esclarecido. Baseando-se no fato de alguns estudos mostrarem hipertrigliceridemia independente de ganho ponderal (Meyer 2001; 2004), especula-se algum mecanismo direto dos APAs no metabolismo lipídico. Sabe-se que o bloqueio 5-HT2c em ratos induz obesidade e resistência insulínica, mas não parece induzir diretamente hiperlipidemia (Tecott et al., 1995; Curzon et al., 2000). Implicação da hiperleptinemia no ganho ponderal induzido por olanzapina e clozapina foi sugerida em estudo que mostrou níveis mais elevados de leptina com essas medicações em relação à risperidona, mesmo após ajuste para o IMC (Atmaca et al., 2003). No entanto, a despeito desse achado, não há evidências que confirmem efeitos deletérios da leptina no metabolismo.

Apesar do desconhecimento do mecanismo de ação exato para o desenvolvimento das dislipidemias no tratamento com APA, a evidência na literatura revela uma tendência que correlaciona aumento de peso e alterações do perfil lipídico. As alterações mais relevantes nos TGs, no CT e no LDL-C estão associadas ao uso de clozapina e olanzapina, drogas que produzem o maior ganho ponderal. Em sentido inverso caminham drogas como o aripiprazol e a ziprasidona, associados a menor aumento de peso e menor risco de dislipidemias. Risperidona e quetiapina possuem efeitos intermediários (Consensus Development Conference on Antipsychotic Drugs and Obesity and Diabetes, 2004).

Dessa forma, as conseqüências do ganho ponderal nos perfis lipídico e glicêmico poderiam explicar as alterações metabólicas induzidas por essas drogas. Sabe-se que a redução ponderal de $5 \%$ a $10 \%$ diminui o CT em cerca de $18 \%$, TGs em $44 \%$ e LDL em até $22 \%$, além de gerar aumentos de HDL de até $27 \%$ (Kreisberg e Oberman, 2003) e, de forma inversa, o ganho ponderal afeta desfavoravelmente o perfil lipídico. No entanto alguns estudos com APA demonstram que essas alterações são independentes do ganho ponderal (Meyer, 2001; 2004), embora a associação se mostre variável ao longo da literatura.

\section{Antipsicóticos típicos e dislipidemias}

Até mesmo os antipsicóticos típicos podem afetar negativamente o perfil lipídico. Uma década após o lançamento da clorpromazina, publicações surgiram mostrando os efeitos adversos dos derivados fenotiazídicos no perfil lipídico, especialmente em relação aos TGs (Clark 1967; 1970). Esses achados foram demonstrados mais uma vez na década de 1980 por Sasaki et al. (1984), que estudaram homens esquizofrênicos tratados com fenotiazídicos ou butirofenonas em relação a controles pareados para sexo e idade, evidenciando que os fenotiazídicos aumentavam os TGs em relação ao grupo tratado com butirofenonas e aos controles, levando ainda a aumento do LDL-C e redução do HDL-C, embora os níveis de CT não tivessem alcançado significância entre os três grupos.

\section{Resultados}

\section{Efeitos dos APAs sobre o perfil lipídico}

Alterações no perfil lipídico são mais prevalentes em indivíduos portadores de esquizofrenia, sob tratamento ou não, entretanto o tipo de alteração varia sobremaneira entre os estudos desenvolvidos, com resultados por vezes contraditórios. A alteração mais freqüente é o aumento no nível dos TGs, achado corroborado pela maioria dos estudos. 0 resultado desses estudos está sumariado na Tabela 3. 
Tabela 3. Sumário de estudos de avaliação de perfil lipídico e terapia com APA

\begin{tabular}{|c|c|c|c|}
\hline Referência & Método do estudo & Droga $(n)$ & Resultados \\
\hline $\begin{array}{l}\text { Kopala et al. } \\
(2006)\end{array}$ & Prospectivo (2 anos) & Quetiapina (39) & Aumento do CT; variações de TG não-significativas \\
\hline $\begin{array}{l}\text { Henderson et } \\
\text { al. (2005) }\end{array}$ & Estudo naturalístico (10 anos) & Clozapina (96) & Não houve variação significativa do TG e do TC \\
\hline $\begin{array}{l}\text { Simpson et al. } \\
(2005)\end{array}$ & Prospectivo (6 semanas) & $\begin{array}{l}\text { Total de 269: olanzapina } \\
\text { (133), ziprasidona (136) }\end{array}$ & $\begin{array}{l}\text { Olanzapina: aumento no CT de } 19,5 \mathrm{mg} / \mathrm{dl} \text {, e com a ziprasidona, diminuição de } 1 \mathrm{mg} / \mathrm{ml} \text {. } \\
\text { TG com olanzapina: aumento de } 26 \mathrm{mg} / \mathrm{dl} \text {, e com ziprasidona diminuiu } 2 \mathrm{mg} / \mathrm{dl} \text {. LDL-C: } \\
\text { aumento de } 13 \mathrm{mg} / \mathrm{dl} \text { com olanzapina, e com ziprasidona, redução de } 1 \mathrm{mg} / \mathrm{dl} \text {. HDL com } \\
\text { variação não significativa }\end{array}$ \\
\hline $\begin{array}{l}\text { Simpson et al. } \\
(2005)\end{array}$ & Prospectivo (6 meses) & $\begin{array}{l}\text { Total de 126: olanzapina } \\
\text { (71), ziprasidona (55) }\end{array}$ & $\begin{array}{l}\text { Com a olanzapina, aumento no CT e no LDL-C; com a ziprasidona, variações não } \\
\text { significativas do CT e do LDL-C }\end{array}$ \\
\hline $\begin{array}{l}\text { Brow e Es- } \\
\text { toup (2005) }\end{array}$ & $\begin{array}{l}\text { Revisão de prontuários } \\
\text { (22 meses) }\end{array}$ & $\begin{array}{l}\text { Total de 191: olanzapina } \\
\text { (103), ziprasidona (88) }\end{array}$ & $\begin{array}{l}\text { Com olanzapina, aumento de } 8 \% \text { no CT, } 11 \% \text { no LDL-C, } 27 \% \text { no TG e diminuição de } \\
4 \% \text { no HDL-C; redução de } 7 \% \text { no CT, } 14 \% \text { no LDL-C, } 7 \% \text { no TG e aumento de } 8 \% \\
\text { no HDL-C com a ziprasidona }\end{array}$ \\
\hline $\begin{array}{l}\text { McQuade et al. } \\
\text { (2004) }\end{array}$ & $\begin{array}{l}\text { Multicêntrico, prospectivo, } \\
\text { duplo-cego e randomizado } \\
\text { (26 semanas) }\end{array}$ & $\begin{array}{l}\text { Total de 317: olanzapina } \\
\text { (161), aripiprazol (156) }\end{array}$ & $\begin{array}{l}\text { Aumento no TG de } 50 \% \text { com a olanzapina e } 18 \% \text { com o aripiprazol. Elevação do } \\
\text { CT de } 47 \% \text { com o uso da olanzapina e } 17 \% \text { com o aripiprazol. Aumento de } 38 \% \text { no } \\
\text { LDL-C com a olanzapina e } 19 \% \text { com o aripiprazol. O HDL-C diminuiu 3,39mg/dl com } \\
\text { a olanzapina e aumentou } 3,61 \mathrm{mg} / \mathrm{dl} \text { com o aripiprazol }\end{array}$ \\
\hline $\begin{array}{l}\text { Almeras et al. } \\
(2004)\end{array}$ & $\begin{array}{l}\text { Ensaio aberto, corte transver- } \\
\text { sal e revisão de prontuários }\end{array}$ & $\begin{array}{l}\text { Total de 87: olanzapina } \\
\text { (42), risperidona (45) }\end{array}$ & $\begin{array}{l}\text { Com olanzapina, maiores concentrações de TG e menores de HDL-C em relação ao } \\
\text { grupo com risperidona }\end{array}$ \\
\hline $\begin{array}{l}\text { Garyfallos et } \\
\text { al. }(2003)\end{array}$ & Prospectivo (8 semanas) & $\begin{array}{l}\text { Total de 50: olanzapina } \\
\text { (25), risperidona }(25)\end{array}$ & $\begin{array}{l}\text { Com olanzapina, aumento significativo no TG; com risperidona, não. Aumento de } \\
\text { peso foi correlacionado ao de TG. Em ambos a variação do CT não foi significativa }\end{array}$ \\
\hline $\begin{array}{l}\text { Pigott et al. } \\
(2003)\end{array}$ & Prospectivo (26 semanas) & $\begin{array}{l}\text { Total de 310: aripiprazol } \\
\text { (50), placebo (260) }\end{array}$ & $\begin{array}{l}\text { Com aripiprazol, diminuição de } 37,2 \mathrm{mg} / \mathrm{dl} \text { no TG e de } 5,1 \mathrm{mg} \text { no LDL-C, e aumento } \\
\text { de } 2 \mathrm{mg} / \mathrm{dl} \text { no HDL-C }\end{array}$ \\
\hline $\begin{array}{l}\text { Atmaca et al. } \\
(2003)\end{array}$ & Prospectivo (6 semanas) & $\begin{array}{l}\text { Total de 45: olanzapina } \\
\text { (15), quetiapina (15), } \\
\text { haloperidol (15) }\end{array}$ & Aumento significativo no TG, sobremaneira nos pacientes em uso de olanzapina \\
\hline $\begin{array}{l}\text { Lindenmeyer } \\
\text { et al. (2003) }\end{array}$ & $\begin{array}{l}\text { Prospectivo e duplo-cego } \\
\text { (14 semanas) }\end{array}$ & $\begin{array}{l}\text { Total de 101: clozapina } \\
(28) \text {, olanzapina }(26)\end{array}$ & Aumento no CT com clozapina ou olanzapina associado a aumento de peso \\
\hline $\begin{array}{l}\text { Atmaca et al. } \\
\text { (2003a) }\end{array}$ & Prospectivo (6 semanas) & $\begin{array}{l}\text { Total de 56: clozapina (14), } \\
\text { olanzapina (14), risperidona } \\
\text { (14), quetiapina (14) }\end{array}$ & Não houve variação significativa do TG \\
\hline $\begin{array}{l}\text { Baymiller et } \\
\text { al. (2002) }\end{array}$ & $\begin{array}{l}\text { Prospectivo, ensaio aberto } \\
\text { (1 ano) }\end{array}$ & Clozapina (50) & $\begin{array}{l}\text { Aumento de 41,8\% no TG; aumento do TG associado ao ganho de peso progressivo } \\
\text { até } 120 \text { dias após, com lenta diminuição; elevação de } 7,5 \% \text { no CT; variação de LDL- } \\
\text { C e HDL-C não-significativa }\end{array}$ \\
\hline $\begin{array}{l}\text { Wirshing et al. } \\
(2002)\end{array}$ & $\begin{array}{l}\text { Revisão de prontuários } \\
\text { (30 meses) }\end{array}$ & $\begin{array}{l}\text { Total de 215: clozapina } \\
\text { (39), olanzapina (32), rispe- } \\
\text { ridona (49), quetiapina (13), } \\
\text { flufenazina (41), zotepina } \\
\text { (1), haloperidol (41) }\end{array}$ & $\begin{array}{l}\text { Aumento no TG de } 34 \% \text { nos pacientes em uso de clozapina; } 38 \% \text { com a olanzapina; } \\
\text { elevação significativa do CT em } 48 \% \text { com clozapina; } 25 \% \text { com olanzapina, } 21 \% \text { com } \\
\text { risperidona, } 25 \% \text { com quetiapina. Diminuição do LDL-C de } 14 \% \text { com olanzapina, } 11 \% \\
\text { com risperidona, } 13 \% \text { com quetiapina. Diminuição de } 10 \% \text { com olanzapina e aumento de } \\
5 \% \text { com risperidona }\end{array}$ \\
\hline Meyer (2002) & $\begin{array}{l}\text { Revisão de prontuários } \\
\text { (1 ano) }\end{array}$ & $\begin{array}{l}\text { Total de 94: risperidona } \\
\text { (47), olanzapina (47) }\end{array}$ & $\begin{array}{l}\text { Em um ano, aumento de } 29,7 \mathrm{mg} / \mathrm{dl} \text { no TG com a risperidona; elevação de } 88,2 \mathrm{mg} / \mathrm{dl} \\
\text { no TG com a olanzapina. Não houve variação significativa no CT }\end{array}$ \\
\hline $\begin{array}{l}\text { Koro et al. } \\
(2002)\end{array}$ & $\begin{array}{l}\text { Coorte retrospectiva } \\
\text { (10 anos) }\end{array}$ & $\begin{array}{l}\text { Total de } 18.309 \text { com } \\
\text { olanzapina ou risperidona; } \\
1.269 \text { casos de dislipidemia }\end{array}$ & $\begin{array}{l}\text { Risco aumentado de } 3 \text { vezes de dislipidemia em comparação com o encontrado com } \\
\text { antipsicóticos típicos }\end{array}$ \\
\hline $\begin{array}{l}\text { Lund et al. } \\
\text { (2001) }\end{array}$ & $\begin{array}{l}\text { Revisão de prontuários } \\
\text { (4 anos) }\end{array}$ & $\begin{array}{l}\text { Clozapina (552); } 2.461 \\
\text { típicos }\end{array}$ & $\begin{array}{l}\text { na faixa etária entre } 20 \text { e } 34 \text { anos (em uso de clozapina) foi encontrado risco relativo } \\
\text { aumento de desenvolvimento de hiperlipidemia ( } R R=2,4 \text { ) }\end{array}$ \\
\hline $\begin{array}{l}\text { Kinon et al. } \\
\text { (2001) }\end{array}$ & $\begin{array}{l}\text { Coorte retrospectiva } \\
\text { (1 ano) }\end{array}$ & $\begin{array}{l}\text { Olanzapina (573), } \\
\text { haloperidol (103) }\end{array}$ & Olanzapina levou a aumento do CT relacionado com ganho de peso \\
\hline
\end{tabular}


Tabela 3. Sumário de estudos de avaliação de perfil lipídico e terapia com APA (continuação)

\begin{tabular}{|c|c|c|c|}
\hline Referência & Método do estudo & Droga $(n)$ & Resultados \\
\hline $\begin{array}{l}\text { Melkerson et } \\
\text { al. (2000) }\end{array}$ & $\begin{array}{l}\text { Coorte prospectiva } \\
(5 \text { meses })\end{array}$ & Olanzapina (14) & $62 \%$ cursaram com aumento do TG; $85 \%$, com aumento no CT \\
\hline $\begin{array}{l}\text { Gaulin et al. } \\
\text { (1999) }\end{array}$ & revisão de prontuários & Clozapina (222) & $\begin{array}{l}\text { Aumento no TG com clozapina; no grupo haloperidol, variações no CT não tiveram } \\
\text { significância }\end{array}$ \\
\hline Osser et al. & $\begin{array}{l}\text { Coorte retrospectiva } \\
\text { (12 semanas) }\end{array}$ & Olanzapina (25) & $\begin{array}{l}\text { Aumento no TG de } 37 \% \text { associado a elevação de peso; aumento no CT não } \\
\text { significativo }\end{array}$ \\
\hline $\begin{array}{l}\text { Vickie et al. } \\
\text { (1997) }\end{array}$ & $\begin{array}{l}\text { Revisão de prontuário } \\
(818 \pm 831 \text { dias })\end{array}$ & Clozapina (63) & Aumento no CT \\
\hline
\end{tabular}

\section{Clozapina}

Vickie et al. (1997), em análise retrospectiva de prontuários envolvendo 63 pacientes sob uso de clozapina, encontraram aumento no CT de 192,7 $\pm 45,4$ para 212,6 $\pm 50,2 \mathrm{mg} / \mathrm{dl}(p<0,001)$. Em outro subgrupo de 19 pacientes não houve variação no TG.

Gaulin et al. (1999) realizaram estudo retrospectivo de revisão de prontuários envolvendo 222 pacientes em uso de clozapina ou haloperidol. 0 estudo encontrou aumento nos TGs dos pacientes em uso de clozapina e diminuição, não significante, no grupo com haloperidol. Variações no CT não obtiveram significância.

Lund et al. (2001) avaliaram retrospectivamente prontuários de 552 pacientes em uso de clozapina, comparando resultados com 2.461 pacientes em tratamento com antipsicóticos típicos. No grupo em uso de clozapina foi encontrado risco relativo (RR) aumentado de desenvolvimento de hiperlipidemia somente entre a faixa etária de 20 a 34 anos $(R R=2,4)$, evento não ocorrido nas demais faixas etárias.

Baymiller et al. (2002) seguiram por um ano 50 pacientes em uso de clozapina e betabloqueadores (BBs). Houve elevação de $41,8 \%$ nos TGs - aumento associado ao ganho de peso e progressivo até um período de 120 dias -, cursando, após, com lenta diminuição. $O$ uso de BBs associado a clozapina não levou a variação significativa nos níveis de TG. Houve também aumento de $7,5 \%$ no CT e variação de LDL e HDL não significativa.

Wirshing et al. (2002) realizaram a revisão de prontuários de 215 pacientes em uso de clozapina, olanzapina, risperidona, quetiapina, haloperidol ou flufenazina. Encontraram aumento nos TGs de $34 \%$ dos pacientes em uso de clozapina $(p=0,01)$ e $38 \%$ com olanzapina ( $p=0,02)$; houve aumento significante (> $200 \mathrm{mg} / \mathrm{dl}$ ) dos níveis do CT em $48 \%$ dos pacientes em uso de clozapina, $25 \%$ com olanzapina, $21 \%$ com risperidona e $25 \%$ com quetiapina. Houve também diminuição de $14 \%$ no LDL-C com a olanzapina, $11 \%$ com risperidona e $13 \%$ com a quetiapina; a clozapina levou à diminuição de $13 \%(p=0,02)$ do HDL-C quando comparada, na fase pré-tratamento, à olanzapina, que levou à diminuição de $10 \%(p=0,03)$, enquanto a risperidona levou ao aumento de $5 \%$.

Atmaca et al. (2003) acompanharam 56 pacientes em uso de clozapina, olanzapina, risperidona, quetiapina ou placebo. Não houve variação significativa do TG.

Lindenmayer et al. (2003), num estudo prospectivo e duplo-cego, avaliaram por 14 semanas 101 pacientes em uso de clozapina, olanzapina, risperidona ou haloperidol, que, previamente, faziam uso de antipsicóticos típicos. Encontraram elevação significativa nos níveis séricos de colesterol nos pacientes em uso de clozapina ou olanzapina associada ao aumento de peso $(p<0,01)$.

Henderson et al. (2005) realizaram um estudo naturalístico envolvendo 96 pacientes tratados com clozapina por um período equivalente a dez anos. Encontraram aumento significativo do IMC nesse grupo, sem alcançarem, entretanto, variação significativa dos TGs e do CT.

\section{Olanzapina}

Osser et al. (1999) estudaram 25 pacientes por 12 semanas em uso de olanzapina, encontrando aumento nos TGs de $37 \%(p<0,04)$ associado a aumento de peso $(p<0,02)$ e elevação não significante no CT $(p=0,76)$. Pacientes que no período fizeram uso de drogas para regulação do perfil lipídico não cursaram com aumento dos TGs. Melkerson et al. (2000) seguiram, por sua vez, 14 pacientes em uso de olanzapina, tendo observado que $62 \%$ cursaram com aumento dos TGs e $85 \%$ com elevação no $\mathrm{CT}$.

Meyer (2001), através de estudo retrospectivo de revisão de prontuários, encontrou a ocorrência de 14 casos de hipertrigliceridemia severa $(600 \mathrm{mg} / \mathrm{dl})$ envolvendo pacientes em uso de olanzapina $(n=12)$ e quetiapina $(n=2)$. Dos pacientes em uso de olanzapina, $64 \%$ obtiveram acréscimo $>200 \mathrm{mg} / \mathrm{dl}$ no período de internamento, ganho não associado a aumento de peso, níveis anteriores de TG ou dose. A análise referente aos pacientes em uso de quetiapina não possuía dados suficientes. Sete pacientes cursaram com taxas superiores a $1.000 \mathrm{mg} / \mathrm{dl}$ de TG, e a média de tempo para o pico foi de nove meses. Todos os pacientes que continuaram fazendo tratamento com associação de hipolipemiantes cursaram com níveis $<300 \mathrm{mg} / \mathrm{dl}$ de TG.

Kinon et al. (2001) realizaram estudo retrospectivo no qual analisaram 573 pacientes em uso de olanzapina, comparando resultados com outros 103 sob uso de haloperidol por pelo menos um ano. 0 aumento do CT nos pacientes em uso de olanzapina foi relacionado com o ganho de peso $(p=0,01)$. A incidência de níveis de CT $>240 \mathrm{mg} / \mathrm{dl}$ entre os grupos no período não foi significante $(p=0,091)$, apesar de os níveis de CT terem sido mais elevados no grupo em uso de olanzapina $(205,7 \mathrm{mg} / \mathrm{dl}$ vs. $189,9 \mathrm{mg} / \mathrm{dl})(p=0,02)$. Dos pacientes em uso de olanzapina, $97 \%$ não cursaram com niveis de CT > 300 $\mathrm{mg} / \mathrm{dl}$. Essa associação sugere que 0 ganho de peso associado ao aumento do CT não parece ser o fator principal da hipercoles- 
terolemia nos pacientes com esquizofrenia, assim como não houve diferença entre os usos de olanzapina e haloperidol.

Koro et al. (2002), numa coorte retrospectiva com seguimento de 4,07 $\pm 2,8$ anos envolvendo 18.309 pacientes sob uso de olanzapina ou risperidona, relataram 1.269 casos de dislipidemia, um risco três vezes aumentado quando em comparação com pacientes em uso de APAs.

Atmaca et al. (2003), em estudo prospectivo por seis semanas com 45 pacientes em uso de olanzapina $(n=15)$, quetiapina $(n=15)$ ou haloperidol $(n=15)$, encontraram aumento significativo nos TGs $(p<0,05)$, sobremaneira nos pacientes em uso de olanzapina $(p<0,01)$.

Garyfallos et al. (2003) acompanharam por oito semanas um grupo de 50 pacientes em uso de risperidona $(n=25)$ ou olanzapina ( $n=25)$. No grupo sob uso da olanzapina houve aumento significativo nos TGs $(p<0,001)$, enquanto na risperidona não houve variação significante $(p>0,1)$. A variação foi correlacionada com aumento de peso e TG $(p<0,001)$. A variação do CT não foi significante em ambos os grupos.

McQuade et al. (2004), em estudo multicêntrico, prospectivo, duplo-cego e randomizado, seguiram 317 pacientes em uso de olanzapina ou aripiprazol por 26 semanas. Observaram aumento de $50 \%$ no TG $(76,4 \mathrm{mg} / \mathrm{dl})$ dos pacientes em uso de olanzapina e $18 \%(6,5 \mathrm{mg} / \mathrm{dl})$ com aripiprazol $(p<0,05)$. A elevação dos níveis séricos do CT não atingiu significância, apesar de haver aumento de $47 \%$ com o uso da olanzapina e $17 \%$ com aripiprazol em relação ao baseline. O LDL-C não variou significantemente, havendo aumento de $38 \%$ com a olanzapina e $19 \%$ com o aripiprazol. O HDL-C diminuiu $3,39 \mathrm{mg} / \mathrm{dl}$ com a olanzapina e aumentou $3,61 \mathrm{mg} / \mathrm{dl} \mathrm{com}$ 0 aripiprazol. A resposta aos sintomas da esquizofrenia, segundo a escala Clinical Global Impressions - Improvement (CGI-I), foi semelhante em ambos os grupos (86\% para a olanzapina e $80 \%$ para 0 aripiprazol, $p>0,05)$.

Brown e Estoup (2005), através de revisão de prontuários de 191 pacientes em uso de olanzapina $(n=103)$ ou ziprasidona ( $n=88$ ) por um período de 22 meses, encontraram aumento de $8 \%$ no CT, $11 \%$ no LDL-C, $27 \%$ nos TGs e diminuição de $4 \%$ no HDL-C com olanzapina e redução de 7\% no CT, $14 \%$ no LDL-C, $7 \%$ nos TGs e aumento de $8 \%$ no HDL-C com a ziprasidona.

\section{Risperidona}

Meyer (2001) avaliou retrospectivamente 76 pacientes em uso de risperidona ou olanzapina pelo período de um ano. Houve aumento de $29,7 \mathrm{mg} / \mathrm{dl}$ dos TGs $(p=0,028)$, alcançando como concentração média $186,4 \mathrm{mg} / \mathrm{dl}$ em um ano no grupo sob uso da risperidona; o grupo com olanzapina teve aumento de $88,2 \mathrm{mg} / \mathrm{dl}$ no TG ( $p=0,01)$, alcançando média de $239,8 \mathrm{mg} / \mathrm{dl}$ no período. Em relação ao $\mathrm{CT}$, não houve variação significativa, apesar de o grupo com olanzapina cursar com aumento maior quando em comparação com a risperidona $(p<0,03)$. Nesse estudo foi verificado que os indivíduos mais jovens (< 60 anos) cursaram com aumento superior ao encontrado nos mais idosos.

Almeras et al. (2004) realizaram estudo envolvendo 87 pacientes em uso de olanzapina $(n=42)$ ou risperidona $(n=45)$. Pacientes em uso de olanzapina obtiveram maiores concentrações de TG e menores de HDL em relação ao grupo em uso de risperidona.

\section{Quetiapina}

Kopala et al. (2006) acompanharam 39 pacientes por um período de dois anos (houve $50 \%$ de perda de seguimento nesse estudo) após primeiro episódio psicótico, instituindo tratamento com quetiapina. Houve aumento significativo do CT em 12 meses $(p<0,05)$ e 24 meses $(p<0,05)$. Variações no TG não foram significativas nem em 12 meses $(p=0,16)$, ou em 24 meses $(p=0,08)$ de acompanhamento. Dez pacientes no início do estudo possuíam IMC $<25 \mathrm{~kg} / \mathrm{m}^{2}$, havendo aumento de $27,6 \%$ no CT e $89,1 \%$ no TG nesse grupo.

\section{Ziprasidona}

Kingsbury et al. (2001) acompanharam 37 pacientes em uso de ziprasidona por seis semanas. Encontraram diminuição do TG $(p<0,02)$ e do CT $(p<0,01)$, independentemente da variação do IMC.

Simpson et al. (2004) seguiram por seis semanas 269 pacientes em uso de olanzapina $(n=133)$ ou ziprasidona $(n=136)$. Pacientes em uso de olanzapina tiveram aumento no CT de $19,5 \mathrm{mg} / \mathrm{dl}$ de uma média no baseline de $183,5 \mathrm{mg} / \mathrm{dl}(p<0,0001)$ e com a ziprasidona, diminuição de $1 \mathrm{mg} / \mathrm{dl}$ de uma média no baseline de $185 \mathrm{mg} / \mathrm{dl}(p=0,48)$. O TG teve aumento de $26 \mathrm{mg} / \mathrm{dl}$ de uma média no baseline de $124 \mathrm{mg} / \mathrm{dl}$ no grupo com olanzapina ( $p=0,0003$ ) e diminuiu $2 \mathrm{mg} / \mathrm{dl}$ de uma média no início de $123 \mathrm{mg} / \mathrm{dl}$ no grupo da ziprasidona ( $p=0.77)$. O LDL-C teve aumento de $13 \mathrm{mg} / \mathrm{dl}$ no grupo da olanzapina de uma média no início de 108mg/dl ( $p<0,0001)$, e com a ziprasidona, diminuição de $1 \mathrm{mg} / \mathrm{dl}$ de uma média no início de $114 \mathrm{mg} / \mathrm{dl}(p=0,78)$. A diferença entre os grupos foi significante em todas as análises. Em nenhum dos tratamentos observou-se variação significativa no HDL-C.

Simpson et al. (2005) realizaram estudo no qual acompanharam por seis meses 126 pacientes em uso de olanzapina $(n=71)$ ou ziprasidona $(n=55)$. Nos pacientes em uso de olanzapina houve aumento no CT $(130 \mathrm{mg} / \mathrm{dl})(p=0,03)$ e no LDL-C $(170 \mathrm{mg} / \mathrm{dl})(p=0,04)$. Nos pacientes em uso de ziprasidona houve variações não significantes do CT $(-1 \mathrm{mg} / \mathrm{dl})(p=0,98) \mathrm{e}$ no LDL-C $(9 \mathrm{mg} / \mathrm{dl})(p=0,29)$.

\section{Aripiprazol}

Pigott et al. (2003) avaliaram 310 pacientes em uso de $15 \mathrm{mg}$ de aripiprazol $(n=50)$ ou placebo $(n=260)$ por um período de 26 semanas. Houve diminuição de $37,2 \mathrm{mg} / \mathrm{dl}$ nos TGs, de $5,1 \mathrm{mg}$ no LDL-C e aumento de $2 \mathrm{mg} / \mathrm{dl}$ no HDL-C no grupo em uso de aripiprazol. Houve também diminuição de $1,26 \mathrm{~kg}$ nesse grupo.

Marder et al. (2003) analisaram cinco estudos prévios placebo-controlados de curta duração (quatro a seis semanas) envolvendo pacientes em uso de aripiprazol, randomicamente, num total de 932 pacientes em uso de aripiprazol, 416 placebo e 201 haloperidol. Não houve aumento significante do CT (1 mg/dl de uma média no início de 192mg/dl) $(n=119)$. Deve ser levado em conta que, num estudo de curta duração, o fator ingesta de alimentos não afetaria significantemente o CT.

\section{Discussão}

A literatura continuamente corrobora o papel dos APAs na desregulação metabólica de pacientes portadores de es- 
quizofrenia, apesar de, atualmente, nem todas as medicações disponíveis possuírem esse perfil. Esse fato contribui destacadamente com o aumento de morbimortalidade associada ao desenvolvimento de DCVs nessa população, podendo ser questionado inclusive o avanço oriundo da prevenção de suicídios obtida com o uso dos APAs. Nesse contexto, deve-se dar relevo ao papel da intervenção sobre fatores de risco, já que ela se acompanha de menor chance de ocorrência de DCV.

O diferente tipo de influência de cada medicação no perfil lipídico demonstra que esse efeito não necessariamente se deve ao tratamento com drogas da classe dos APAs, havendo possibilidades de intervir sem essa associação. Existe uma tendência no tratamento com a clozapina ou olanzapina de aumento nos TGs. Com a risperidona essa associação não é tão freqüente ou intensa. A olanzapina possui maior risco de alteração quando comparada a quaisquer outros APAs. Há uma tendência nos estudos para que o aumento dos TGs caminhe conjuntamente com o do CT, do LDL-C e com a diminuição do HDL-C, associadamente com ganho ponderal. Essa associação, já comprovada na população geral, fica prejudicada principalmente devido ao pequeno número das amostras da maioria dos estudos. Além disso, a avaliação de CT, LDL-C e HDL-C ainda não foi tão bem fundamentada quanto a categoria dos TGs, havendo muita controvérsia na literatura. Não existem dados que permitam avaliar adequadamente 0 risco de transtornos metabólicos com a quetiapina. Assim como com a risperidona, o risco de eventos metabólicos pode estar aumentado quando são associadas medicações que levem ao acréscimo de peso. Com a ziprasidona e o aripiprazol, entretanto, foram observados efeitos neutros nos níveis lipídicos, havendo, inclusive, possibilidade de redução, principalmente quando há tratamento prévio com medicações que influenciem negativamente essas medidas. Em um estudo, pacientes em uso de aripiprazol cursaram com menor risco de desenvolvimento de SM do que aqueles que utilizavam olanzapina.

A análise desses estudos é prejudicada ainda por uma série de fatores que confundem a terapia medicamentosa antipsicótica utilizada anteriormente aos APAs e hábitos de vida de cada população. Essa revisão da literatura possui algumas limitações. Estudos de diferentes metodologia e qualidade de execução foram tratados igualmente, sem uso de critérios mais estritos. Relatos de caso, estudos retrospectivos ou abertos formam a maior parte do estado-da-arte, o que prejudica uma análise mais confiável dos resultados obtidos.

\section{Manejo com APA}

\section{Avaliação de fatores de risco}

Nessa etapa visa-se avaliar pacientes possuidores de risco aumentado para DCV e transtornos metabólicos: obesidade (peso e altura para aferição do IMC), dislipidemia, hiperglicemia/diabetes, hipertensão. Também devem ser analisados: estilo de vida, dieta, tabagismo, sedentarismo e fatores de estresse psicossociais. Necessária se faz, igualmente, a avaliação da história familiar de doenças cardiovasculares e metabólicas. De posse desses dados, o médico poderá definir sua conduta com maior segurança e estar mais atento para determinados aspectos de maneira individualizada.

\section{Escolha do antipsicótico}

De acordo com os dados obtidos na primeira etapa, devem ser analisados riscos e benefícios na escolha de cada droga. Efeitos adversos e modificação nos fatores de risco devem ser discutidos com o paciente e sua família com 0 intuito de torná-los mais participativos e capazes de intervir precocemente. Escolher medicações com menores efeitos colaterais metabólicos auxilia a prevenção do desenvolvimento de fatores de risco (Tabela 2). Se o paciente evolui com ganho de peso e boa resposta ao tratamento, devem ser consideradas as vantagens e as desvantagens da mudança de medicação, inclusive devido à possível associação entre ganho de peso e resposta da droga (Newcomer, 2005). Também deve ser ponderado o uso concomitante de outras medicações que interfiram no perfil metabólico, como o valproato e o lítio, preconizando-se, nessa situação, medicações de menor impacto metabólico.

\section{Monitorização}

Em 2004, na conferência para desenvolvimento do consenso das associações americanas de psiquiatria, obesidade e diabetes, foi criado um protocolo para monitorização clinicolaboratorial para paciente sob uso de APA. Nesse protocolo, caso o paciente possua o perfil lipídico normal na primeira análise, sugere-se que ele deva ser avaliado novamente após cinco anos. Meyer e Koro (2004) sugerem avaliação do perfil lipídico no primeiro ano quadrimestralmente caso o paciente esteja em uso de clozapina, olanzapina ou quetiapina. Se os níveis se mantiverem normais, a avaliação deve ser feita anualmente, e, caso haja alterações, deve-se manter avaliação quadrimestral. Quando há uso de risperidona, ziprasidona ou aripiprazol, a análise deve ser feita anualmente, caso não haja suspeita de dislipidemias (Tabela 4). Caso o paciente venha a apresentar alterações significativas, intervenções individualizadas são sugeridas. Alterações maiores que $5 \%$ no peso, assim como hiperglicemia/diabetes ou hiperlipidemia, podem indicar mudança da medicação e/ou acompanhamento por um especialista. Deve-se ficar atento para sinais de descompensação metabólica como confusão, retardo psicomotor, dor abdominal, poliúria e polidipsia, que necessitam de atendimento de emergência (Consensus Development Conference on Antipsychotic Drugs and Obesity and Diabetes, 2004; Meyer, 2001). Paton et al. (2004) encontraram registro do perfil lipídico em apenas $3,5 \%$ dos prontuários de 606 pacientes sob uso de APA.

\section{Mudança de antipsicótico}

Os maiores riscos envolvidos na mudança do antipsicótico são a perda dos efeitos benéficos desenvolvidos e o surgimento de efeitos adversos durante o processo de descontinuação. Existem poucos estudos sistematizados de estratégias para mudança de antipsicóticos, e os resultados são contraditórios. A conferência para desenvolvimento do consenso sobre drogas antipsicóticas, obesidade e diabetes de 2004 indica descontinuação e acréscimo graduais da primeira droga e da substituta, obedecendo ao perfil da droga. É sugerida cautela maior na retirada da clozapina pelo risco exacerbações do quadro psicótico (Consensus Development Conference on Antipsychotic Drugs and Obesity and Diabetes, 
Tabela 4. Protocolo de monitorização para pacientes em uso de APA

\begin{tabular}{lcccccc}
\hline & Início & $\begin{array}{c}\text { Quatro } \\
\text { sema- } \\
\text { nas }\end{array}$ & $\begin{array}{c}\text { Oito } \\
\text { sema- } \\
\text { nas }\end{array}$ & $\begin{array}{c}\text { Doze } \\
\text { sema- } \\
\text { nas }\end{array}$ & $\begin{array}{c}\text { Quadri- } \\
\text { mestral- } \\
\text { mente }\end{array}$ & $\begin{array}{c}\text { Anual- } \\
\text { mente }\end{array}$ \\
\hline $\begin{array}{c}\text { História fami- } \\
\text { liar/pessoal }\end{array}$ & $\mathrm{X}$ & & & & & $\mathrm{X}$ \\
$\begin{array}{c}\text { Peso (IMC) } \\
\text { Circunferência } \\
\text { abdominal }\end{array}$ & $\mathrm{X}$ & $\mathrm{X}$ & $\mathrm{X}$ & $\mathrm{X}$ & $\mathrm{X}$ & \\
$\begin{array}{c}\text { Tensão } \\
\text { arterial }\end{array}$ & $\mathrm{X}$ & & & $\mathrm{X}$ & & $\mathrm{X}$ \\
Glicemia & $\mathrm{X}$ & & & $\mathrm{X}$ & $\mathrm{X}$ \\
Perfil lipídico & $\mathrm{X}$ & & & $\mathrm{X}$ & $\mathrm{X}$ \\
\hline
\end{tabular}

Obs.: Avaliações mais freqüentes podem ser realizadas de acordo com quadro clínico.

IMC: índice de massa corporal.

2004). Casey et al. (2003) desenvolveram estudo multicêntrico, randomizado e aberto avaliando a mudança de outro antipsicótico para aripiprazol com 311 pacientes não encontrando variações na eficácia e segurança entre quaisquer das estratégias desenvolvidas (início ou descontinuação abrupta, assim como através de variações graduais nas dosagens das drogas).

\section{Hábitos de vida}

A terapêutica se inicia no incentivo a hábitos de vida mais saudáveis como controle de peso, mudanças alimentares, exercício físico e combate ao tabagismo. Caso o sucesso não seja alcançado, deve ser considerado o uso associado de medicações (III Diretrizes de Dislipidemias e Prevenção da Aterosclerose, 2001).

\section{Intervenção farmacológica}

Para o tratamento das dislipidemias sugere-se avaliação inicialmente após dois meses e, posteriormente, a cada quatro e seis meses. As medicações devem ser mantidas até normalização dos níveis do perfil lipídico. Deve-se estar atento ao comportamento dos APAs em relação ao perfil lipídico, já que existe tendência de aumento inicial com posterior redução (Meltzer et al., 2001). Os indivíduos devem ser observados, a priori, até estabilização dos níveis, excetuando-se quando os TGs atingirem níveis superiores a $400 \mathrm{mg} / \mathrm{dl}$ devido ao risco de pancreatite aguda. Alguns medicamentos podem ser úteis no manejo das alterações do perfil lipídico, tais como:

- fibratos: redução dos TGs em até $70 \%$ e do CT em até $20 \%$; aumento do HDL-C em até $25 \%$ (exs.: benzafibrato e genfibrozil);

- ácido nicotínico: redução dos TGs em até $80 \%$ e do CT em até $30 \%$; aumento do HDL-C em até $35 \%$ (exs.: niacina, acipimox);

- ácido graxo ômega 3: deve ser usado em doses altas, o que limita seu uso. Indicado em casos específicos de hipertrigliceridemia refratária;
- ezetimiba: redução dos TGs em até $5 \%$ e do LDL-C em até $18 \%$; aumento do HDL-C em $1 \%$;

- estatinas: redução dos TGs em até $20 \%$, do CT em até $30 \%$ e do LDL-C em até 40\%; aumento do HDL-C em até $10 \%$ (exs.: sinvastatina, atorvastatina) (III Diretrizes de Dislipidemias e Prevenção da Aterosclerose, 2001; I Diretriz Brasileira de Diagnóstico e Tratamento da Síndrome Metabólica, 2005).

Pacientes diabéticos podem se beneficiar mais da terapia com estatinas do que não-diabéticos, principalmente pela menor ação do ácido ômega 3 e do genfibrozil nesses pacientes. $O$ ácido nicotínico é relativamente contra-indicado devido a cursar com resistência insulínica e hiperglicemia (Meyer et al., 2001).

Não havendo resposta satisfatória, podem-se associar medicações. Essa atitude, além de promover melhores resultados, permite o uso de doses inferiores de cada medicamento, proporcionando redução dos efeitos colaterais e aumentando sua tolerância. Entretanto deve ser feita com cautela (III Diretrizes de Dislipidemias e Prevenção da Aterosclerose, 2001).

\section{Outras intervenções}

Reguladores do apetite devem ser utilizados com cautela devido ao risco intrínseco de desenvolvimento de psicoses. 0 topiramato e a sibutramina podem alterar o estado mental dos pacientes, agravando os sintomas da esquizofrenia. Além disso, os estudos já realizados são poucos e envolvem populações muito reduzidas (nizatadina, amantadina, topiramato e sibutramina) (Wirshing, 2004). 0 orlistate não possui ação no sistema nervoso central (SNC), sugerindo sua escolha como medicação para tratamento da obesidade (Henderson et al., 2001).

Faulkner et al. (2003) realizaram uma revisão sistemática que avaliou 16 estudos de intervenções farmacológicas e comportamentais para controle de peso em pacientes com esquizofrenia. Apenas três estudos revelaram sucesso na diminuição de pelo menos $5 \%$ do peso corporal.

Apesar de poucos relatos de sucesso, a cirurgia bariátrica para obesidade mórbida é geralmente contra-indicada a pacientes psicóticos devido aos riscos de não-aderência à dieta e aos cuidados no pós-operatório (Wirshing et al., 2004).

\section{Intervenção comportamental}

Esse é um terreno promissor para o ganho de peso induzido pelos APAs. Atitudes simples como pesar os pacientes, solicitar-Ihes que façam um diário alimentar e encaminhá-los a um nutricionista se mostraram intervenções úteis. Pesquisas recentes com grupos de apoio ao controle do peso associado ao tratamento especificamente elaborado para pacientes com esquizofrenia mostraram resultados preliminares promissores (Wirshing et al., 2004).

\section{Conclusão}

É de fundamental importância que os psiquiatras adquiram uma postura pró-ativa na pesquisa por dislipidemias e outros transtornos metabólicos nos pacientes portadores de transtornos mentais, em especial a população em uso de APA. 
Associado ao uso de clozapina e, proeminentemente, olanzapina, existe maior risco de desenvolvimento de dislipidemias. A risperidona possui influência modesta, e a quetiapina, dados discordantes. A ziprasidona e o aripiprazol, apesar de pouca evidência acumulada, possuem efeitos neutros sobre 0 perfil lipídico. $\mathrm{O}$ acréscimo dos TGs é o mais evidente, havendo ainda aumento no CT, no LDL-C e diminuição do HDL-C, sem tanta consistência literária quanto os TGs. Sugere-se também associação entre dislipidemia e acréscimo ponderal. Esses fatores contribuem, portanto, com uma maior incidência de DCV nessa população específica.

Ante a existência de tantos eventos metabólicos adversos, poderia ser questionada a propriedade dessa terapêutica em detrimento dos antipsicóticos típicos, mais seguros nesse âmbito. Entretanto deve ser levado em conta todo o impacto positivo motivado por essa classe de medi- camentos (de Sena et al., 2003). A adesão ao tratamento aumentou bastante devido à diminuição dos efeitos extrapiramidais. Há controle mais eficiente dos sintomas negativos e positivos, assim como possível melhora na cognição, viabilizando maior interação social e prática de atividades laborais, contribuição essas fundamentais na consolidação de uma melhor qualidade de vida na esquizofrenia (Meltzer, 2001; Newcomer, 2005). É de fundamental importância que haja interação multidisciplinar no manejo e na identificação das disfunções metabólicas, criando-se também um elo com os cuidadores, peças-chave da obtenção de sucesso no tratamento.

Sugere-se o desenvolvimento de estudos controlados para avaliação mais precisa da relação entre uso de APAs e desenvolvimento de dislipidemias com pacientes psiquiátricos a fim de se progredir quanto ao seu prognóstico.

\section{Referências}

I Diretriz Brasileira de Diagnóstico e Tratamento da Síndrome Metabólica. Arquivos Brasileiros de Cardiologia, 84(Supl 1): 3-28, 2005.

III Diretrizes Brasileiras Sobre Dislipidemias e Diretriz de Prevenção da Aterosclerose do Departamento de Aterosclerose da Sociedade Brasileira de Cardiologia. Arq Bras Cardiol, 77(Supl 3): 1-48, 2001.

American Heart Association and National Heart, Lung and Blood Institute. Cardiovascular Disease Cost. Available at: <http://www. americanheart.org/presenter.jhtml?identifier $=4475>$. Access in: 10 Sep. 2006

Allison DB, Mentore JL, Heo M, Chandler LP, Cappelleri JC, Infante MC, Weiden PJ. Antipsychotic-induced weight gain: a comprehensive research synthesis. Am J Psychiatry, 156: 1686-96, 1999

Almeras N, Despres JP, Villeneuve J, Demers MF, Roy MA, Cadrin C, Mottard JP, Bouchard RH. Development of an atherogenic metabolic risk factor profile associated with the use of atypical antipsychotics. J Clin Psychiatry, 65(4): 557-64, 2004.

American Diabetes Association; American Psychiatric Association; American Association of Clinical Endocrinologists; North American Association for the Study of Obesity. Consensus Development Conference on Antipsychotic Drugs and Obesity and Diabetes. Diabetes Care, 27(2): 596-601, 2004.

Atmaca M, Kuloglu M, Tezcan E, Gecici O, Ustundag B. Weight gain, serum leptin and triglyceride levels in patients with schizophrenia on antipsychotic treatment with quetiapine, olanzapine and haloperidol. Schizophr Res, 60(1): 99-100, 2003.

Atmaca M, Kuloglu M, Tezcan E, Ustundag B. Serum leptin and triglyceride levels in patients on treatment with atypical antipsychotics. J Clin Psychiatry, 64(5): 598-604, 2003.

Baptista T. Body weight gain induced by antipsychotic drugs: mechanisms and management. Acta Psychiatr Scand, 100(1): 3-16, 1999.
Bassitt DP, Louza MR. Schizophrenia and use of antipsychotics: prevalence of overweight, lipid abnormalities and diabetes mellitus. International Congress on Schizophrenia Research, 2003.

Baymiller SP, Ball P, McMahon RP, Buchanan RW. Serum glucose and lipid changes during the course of clozapine treatment: the effect of concurrent beta-adrenergic antagonist treatment. Schizophr Res, 59 (1): 49-57, 2003.

Bouchard RH, Demers M, Simoneau I, Almeras N, Villeneuve J, Mottard JP, Cadrin C, Lemieux I, Després JP. Atypical antipsychotics and cardiovascular risk in schizophrenic patients J Clin Psychopharmacol, 21(1): 110-1, 2001.

Breier A, Berg PH, Thakore JH, Naber D, Gattaz WF, Cavazzoni P, Walker DJ, Roychowdhury SM, Kane JM. Olanzapine versus ziprasidone: results of a 28-week double-blind study in patients with schizophrenia. Am J Psychiatry, 162(10): 1879-87, 2005.

Brown RR, Estoup MW. Comparison of the metabolic effects observed in patients treated with ziprasidone versus olanzapine. Int Clin Psychopharmacol, 20(2): 105-12, 2005.

Brown S. Excess mortality of schizophrenia. A meta-analysis. $\mathrm{Br} \mathrm{J}$ Psychiatry, 171: 502-8, 1997.

Caldwell CB, Gottesman II. Schizophrenics kill themselves too: a review of risk factors for suicide. Schizophr Bull, 16(4): 57189, 1990.

Casey DE, Carson WH, Saha AR, Liebeskind A, Ali MW, Jody D, Ingenito GG; Aripiprazole Study Group. Switching patients to aripiprazole from other antipsychotic agents: a multicenter randomized study. Psychopharmacology, 166(4): 391-9, 2003.

Casey DE. Dyslipidemia and atypical antipsychotic drugs. J Clin Psychiatry, 65(Suppl 18): 27-35, 2004.

Clark ML, Ray TS, Paredes A, Ragland RE, Costiloe JP, Smith CW, Wolf S. Chlorpromazine in women with chronic schizophrenia: the effect on cholesterol levels and cholesterol-behavior relationships. Psychosom Med, 29(6): 634-42, 1967. 
Clark M, Dubowski K, Colmore J. The effect of chlorpromazine on serum cholesterol in chronic schizophrenic patients. Clin Pharmacol Ther, 11(6): 883-9, 1970.

Cohn T, Prud'homme D, Streiner D, Kameh H, Remington G. Characterizing coronary heart disease risk in chronic schizophrenia: high prevalence of the metabolic syndrome. Can J Psychiatry, 49(11): 753-60, 2004.

Curzon G, Gibson EL, Oluyomi AO. Appetite suppression by commonly used drugs depends on $5-\mathrm{HT}$ receptors but not on 5-HT availability. Trends Pharmacol Sci, 18(1): 21-5, 1997.

de Sena EP, Sampaio AS, Quarantini LC, Oliveira IR. Diabetes mellitus e antipsicóticos atípicos. Rev Bras Psiquiatr, 25(4): 253-7, 2003.

Dixon L, Weiden P, Delahanty J, Goldberg R, Postrado L, Lucksted A, Lehman A. Prevalence and correlates of diabetes in national schizophrenia samples. Schizophr Bull, 26(4): 903-12, 2000.

Enger C, Weatherby L, Reynolds RF, Glasser DB, Walker AM. Serious cardiovascular events and mortality among patients with schizophrenia. J Nerv Ment Dis, 192(1): 19-27, 2004.

Faulkner G, Soundy AA, Lloyd K. Schizophrenia and weight management: a systematic review of interventions to control weight. Acta Psychiatr Scand, 108(5): 324-32, 2003.

Fontaine KR, Heo M, Harrigan EP, Shear CL, Lakshminarayanan $M$, Casey DE, Allison DB. Estimating the consequences of anti-psychotic induced weight gain on health and mortality rate. Psychiatry Res, 101(3): 277-88, 2001.

Garyfallos G, Dimelis D, Kouniakis P, Sidiropoulos N, Karastergiou A, Lavrentiadis G, Giouzepas J, Fokas K. Olanzapine versus risperidone: weight gain and elevation of serum triglyceride levels. Eur Psychiatry, 18(6): 320-1, 2003.

Gaulin BD, Markowitz JS, Caley CF, Nesbitt LA, Dufresne RL. Clozapine-associated elevation in serum triglycerides. Am J Psychiatry, 156: 1270-2, 1999.

Hagg S, Lindblom Y, Mjorndal T, Adolfsson R. High prevalence of the metabolic syndrome among a Swedish cohort of patients with schizophrenia. Int Clin Psychopharmacol, 21(2): 93-8, 2006.

Helgason L. Twenty years' follow-up of first psychiatric presentation for schizophrenia: what could have been prevented? Acta Psychiatr Scand, 81(3): 231-5, 1990.

Henderson DC. Clozapine: diabetes mellitus, weight gain, and lipid abnormalities. J Clin Psychiatry, 62(23): 39-44, 2001.

Henderson DC, Nguyen DD, Copeland PM, Hayden DL, Borba CP, Louie PM, Freudenreich O, Evins AE, Cather C, Goff DC. Clozapine, diabetes mellitus, hyperlipidemia and cardiovascular risks and mortality: results of a 10 -year naturalistic study. J Clin Psychiatry, 66(9): 1116-21, 2005.

Keefe RS, Silva SG, Perkins DO, Lieberman JA. The effects of atypical antipsychotic drugs on neurocognitive impairment in schizophrenia: a review and meta-analysis. Schizophr Bull, 25(2): 201-22, 1999.

Kelly DL, Conley RR, Carpenter WT. First-episode schizophrenia: a focus on pharmacological treatment and safety considerations. Drugs, 65(8): 1113-38, 2005.

Kingsbury SJ, Fayek M, Trufasiu D, Zada J, Simpson GM. The apparent effects of ziprasidone on plasma lipids and glucose. J Clin Psychiatry, 62(5): 347-9, 2001

Kinon BJ, Basson BR, Gilmore JA, Tollefson GD. Long-term olanzapine treatment: weight change and weight-related health factors in schizophrenia. J Clin Psychiatry, 62(2): 92100, 2001.

Kreisberg RA, Oberman A. Medical management of hyperlipidemia/ dyslipidemia. J Clin Endocrinol Metab, 88(6):2445-61, 2003.

Knopp RH. Drug treatment of lipid disorders. N Engl J Med, 341(7): 498-511, 1999.
Kopala LC, Good KP, Milliken H, Buiteman C, Woodley H, Rui Q, Whitehorn D, Love L, Balshaw R, Kiss I, Honer WG. Treatment of a first episode of psychotic illness with quetiapine: an analysis of 2 year outcomes. Schizophrenia Research, 81: 29-39, 2006.

Koro CE, Fedder DO, L'Italien, GJ, Weiss S, Magder LS, Kreyenbuhl J, Revicki D, Buchanan RW. An assessment of the independent effects of olanzapine and risperidone exposure on the risk of hyperlipidemia in schizophrenic patients. Arch Gen Psychiatry, 59: 1021-6, 2002.

Lamberti JS, Bellnier T, Schwarzkopf SB. Weight gain among schizophrenic patients treated with clozapine. Am J Psychiatry, 149(5): 689-90, 1992.

Leadbetter R, Shutty M, Pavalonis D, Vieweg V, Higgins P, Downs M. Clozapine-induced weight gain: prevalence and clinical relevance. Am J Psychiatry, 149(1): 68-72, 1992.

Lindenmayer J, Smith RC, Bark N, Khandat A. Glucose and lipid metabolism in patients treated with atypical and conventional antipsychotic medication. Psychopharmacology Research Unit, Manhattan Psychiatric International Congress on Schizophrenia Research, 2003.

Lindenmayer JP, Czobor P, Volavka J, Citrome L, Sheitman B, McEvoy JP, Cooper TB, Chakos M, Lieberman JA. Changes in glucose and cholesterol levels in patients schizophrenia treated with typical or atypical with antipsychotics. Am J Psychiatry, 160(2): 290-6, 2003.

Lund BC, Perry PJ, Brooks JM, Arndt S. Clozapine use in patients with schizophrenia and the risk of diabetes, hyperlipidemia and hypertension: a claims-based approach. Arch Gen Psychiatry, 58(12): 1172-6, 2001.

Marder SR, McQuade RD, Stock E, Kaplitac S, Marcusc R, Safferman AZ, Saha A, Alid M, Iwamoto T. Aripiprazole in the treatment of schizophrenia: safety and tolerability in short-term, placebo-controlled trials. Schizophr Res, 61(2-3): 123-36, 2003.

McEvoy JP, Meyer JM, Goff DC, Nasrallah HA, Davis SM, Sullivan L, Meltzer HY, Hsiao J, Stroup TS, Lieberman JA. Prevalence of the metabolic syndrome in patients with schizophrenia: baseline results from the Clinical Antipsychotic Trials of Intervention Effectiveness (Catie) schizophrenia trial and comparison with national estimates from Nhanes III B. Schizophr Res, 80: 19-32, 2005.

McQuade RD, Stock E, Marcus R, Jody D, Gharbia NA, Vanveggel S, Archibald $\mathrm{D}$, Carson WH. A comparison of weight change during treatment with olanzapine or aripiprazole: results from a randomized, double-blind study. J Clin Psychiatry, 65(18): 47-56, 2004.

Melkersson KI, Hulting AL, Brismar KE. Elevated levels of insulin, leptin, and blood lipids in olanzapine-treated patients with schizophrenia or related psychoses. J Clin Psychiatry, 61(10): 742-9, 2000.

Meltzer HY, Okayli G. Reduction of suicidality during clozapine treatment of neuroleptic-resistant schizophrenia: impact on risk-benefit assessment. Am J Psychiatry, 152(2): 183-90, 1995.

Meltzer HY. Putting metabolic side effects into perspective risks: versus benefits of atypical antipsychotics. J Clin Psychiatry, 62(27): 35-9, 2001.

Menezes PR, Mann AH. Mortality among patients with non-affective functional psychoses in a metropolitan area of South-Eastern Brazil. Rev Saúde Pública, 30(4): 304-9, 1996.

Meyer JM. Novel antipsychotics and severe hyperlipidemia. J Clin Psychopharmacol, 21(4): 369-74, 2001.

Meyer JM. Effects of atypical antipsychotics on weight and serum lipid levels. J Clin Psychiatry, 62(Suppl 27): 27-34. 2001

Meyer JM, Koro CE. The effects of antipsychotic therapy on serum lipids: a comprehensive review. Schizophr Res, 70 (1): 1-17, 2004.

Newcomer JW. Second-generation (atypical) antipsychotics and metabolic effects: a comprehensive literature review. CNS Drugs, 19(1): 1-93, 2005.

Osser DN, Najarian DM, Dufresne RL. Olanzapine increases weight and serum triglyceride levels. J Clin Psychiatry, 60(11): 767-70, 1999. 
Paton C, Esop R, Young C, Taylor D. Obesity, dyslipidaemias and smoking in an inpatient population treated with antipsychotic drugs. Acta Psychiatr Scand, 110(4): 299-305, 2004.

Pigott TA, Carson WH, Saha AR, Torbeyns AF, Stock EG, Ingenito GG; Aripiprazole Study Group. Aripiprazole for the prevention of relapse in stabilized patients with chronic schizophrenia: a placebo-controlled 26-week study. J Clin Psychiatry, 64(9): 1048-56, 2003.

Sasaki J, Kumagae G, Sata T, Kuramitsu M, Arakawa K. Decreased concentration of high density lipoprotein cholesterol in schizophrenic patients treated with phenothiazines. Atherosclerosis, 51(2-3): 163-9, 1984.

Silva de Lima M, de Jesus Mari J, Breier A, Maria Costa A, Ponde de Sena E, Hotopf M. Quality of life in schizophrenia: a multicenter, randomized, naturalistic, controlled trial comparing olanzapine to first-generation antipsychotics. J Clin Psychiatry, 66(7): 8318, 2005.

Simpson GM, Weiden P, Pigott T, Murray S, Siu CO, Romano SJ. Sixmonth, blinded, multicenter continuation study of ziprasidone versus olanzapine in schizophrenia. Am J Psychiatry, 162: 1535-8, 2005.

Simpson GM, Glick ID, Weiden P, Pigott T, Siu CO, Romano SJ. Randomized, controlled, double-blind multicenter comparison of the efficacy and tolerability ofziprasidone and olanzapine in acutely ill inpatients with schizophrenia or schizoaffective disorder. Am J Psychiatry, 161: 1837-47, 2004.
Sowell MO, Mukhopadhyay N, Cavazzoni P, Shankar S, Steinberg HO, Breier A, Beasley CM Jr, Dananberg J. Hyperglycemic clamp assessment of insulin secretory responses in normal subjects treated with olanzapine, risperidone, or placebo. J Clin Endocrinol Metab, 87(6): 2918-23, 2002.

Stip E, Lussier I, Ngan E, Mendrek A, Liddle P. Discriminant cognitive factors in responder and non-responder patients with schizophrenia. Eur Psychiatry, 14(8): 442-50, 1999.

Tecott LH, Sun LM, Akana SF, Strack AM, Lowenstein DH, Dallman MF, Julius D. Eating disorder and epilepsy in mice lacking $5-\mathrm{HT} 2 \mathrm{C}$ serotonin receptors. Nature, 374(6522): 542-6, 1995.

Weiden PJ, Mackell JA, McDonnell DD. Obesity as a risk factor for antipsychotic noncompliance. Schizophr Res, 66(1): 51-7, 2004.

Weissman EM, Zhu CW, Schooler NR, Goetz RR, Essock SM. Lipid monitoring in patients with schizophrenia prescribed secondgeneration antipsychotics. J Clin Psychiatry, 67(9): 1323-6, 2006.

Wetterling T, Mussigbrodt HE. Weight gain: side effect of atypical neuroleptics? J Clin Psychopharmacol, 19(4): 316-21, 1999.

Wirshing DA, Boyd JA, Meng LR, Ballon JS, Marder SR, Wirshing WC. The effects of novel antipsychotics on glucose and lipid levels. J Clin Psychiatry, 63(10): 856-65, 2002.

Wirshing DA. Schizophrenia and obesity: impact of antipsychotic medications. J Clin Psychiatry, 65(18): 13-26, 2004. 